\title{
Teknik Pengisian Ulang Baterai Alkaline Nonrecharable Bekas Untuk Memperpanjang Umur Pemakaian
}

\author{
Techniques For Charging Used Non-Rechargeable Alkaline Batteries \\ To Prolong Its Use
}

\author{
I Nyoman Wahyu Satiawan*, Supriono, Ida Bagus Fery. Citarsa, \\ I Made Budi Suksmadana, Warindi \\ Jurusan Teknik Elektro, Fakultas Teknik, Universitas Mataram.
}

*Corresponding Author Email: warindidulrachman@gmail.com

Manuscript received: 08-12-2020. Accepted: 27-10-2021

\begin{abstract}
ABSTRAK
Baterai alkalin merupakan salah satu jenis baterai yang didesain untuk sekali pakai. Akibatnya sampah atau limbah baterai alkalin sangat banyak. Untuk mengurangi dampak limbah baterai alkalin dirasa perlu adanya konservasi baterai yaitu dengan memperpanjanag usia pakainya, sehingga menunda baterai tersebut menjadi limbah. Cara mudahnya adalah mengisi ulang baterai agar dapat digunakan kembali. Walaupun baterai alkaline merupakan baterai yang sekali pakai, namun dari karakteristik reaksi elektrokimianya terlihat bahwa reaksi kimia tersebut dapat dibalik sehingga terdapat kemungkinan bahwa baterai dapat diisi ulang. Beberapa batasan dalam pengisian ulang diantaranya menyangkut kondisi baterai, strategi pengisian ulang, batas jumlah siklus pengisian dan kapasitas baterai saat diisi ulang. Paper ini membahas prosedur konservasi baterai alkalin bekas untuk meningkatkan waktu guna dan sekaligus mengurangi dampak negatif limbah baterai terhadap lingkungan. Tahap-tahap experimen pengisian baterai adalah: 1) pendeteksian kualitas baterai alkalin bekas, 2) penentuan cara pengisian ulang yang tepat dan 3) perkiraan jumlah siklus isi ulang yang aman sebelum akhirnya didaur ulang. Hasil experimen menunjukkan bahwa: 1) pendeteksian batere yang masih bisa diisi kembali dapat dilakukan dengan metode pengisian awal singkat dan pengecekan apakah terjadi penambahan kapasitas batere, 2) metode gabungan tegangan konstan dan arus kontan adalah yang paling cepat dan aman dalam mengisi ulang batere alkaline, 3) rata-rata batere alkaline dapat diisi ulang hingga 8 kali.
\end{abstract}

Kata kunci: limbah; baterai; konservasi; pengisian-ulang

\footnotetext{
ABSTRACT

Alkaline battery is one type of battery that is designed for single use. As a result, there is a lot of waste or alkaline battery waste. To reduce the impact of alkaline battery waste, it is deemed necessary to conserve batteries, namely by extending their service life, thereby delaying the battery to become
} 
waste. The easy way is to recharge the battery so that it can be used again. Although alkaline batteries are disposable batteries, from the characteristics of the electrochemical reactions it can be seen that the chemical reactions can be reversed so that there is a possibility that the batteries can be recharged. Some of the limitations in recharging include the condition of the battery, recharging strategy, the limit on the number of charging cycles and the capacity of the battery when it is recharged. This paper discusses the procedure for conserving used alkaline batteries to increase the use time and at the same time reduce the negative impact of battery waste on the environment. The stages of the battery charging experiment are: 1) detecting the quality of used alkaline batteries, 2) determining the proper way of recharging and 3) estimating the number of safe recharge cycles before being recycled. The experimental results show that: 1) the detection of rechargeable batteries can be carried out by the short initial charge method and checking whether there is an increase in battery capacity, 2) the combined method of constant voltage and constant current is the fastest and safest way to recharge alkaline batteries, 3) the average alkaline battery can be recharged up to 8 times.

Keywords: battery; waste; conservation; recharging

\section{PENDAHULUAN}

Baterai alkalin sudah digunakan pada piranti-piranti teknologi secara luas selama bertahun-tahun. Pertumbuhan pasar baterai alkalin global diperkirakan mencapai USD 6,8 Milyar pada akhir tahun 2024 dari USD 5,9 Milyar pada tahun 2018 (Fast, 2020). Di Indonesia, perkembangan industri baterai berkembang pesat. Hingga tahun 2013 jumlah unit usaha industri besar dan sedang yang bergerak di bidang batu baterai kering meningkat 6,74\% ( Kemenprin. 2020).

Baterai alkalin termasuk golongan baterai kering (baterai primer) yang hanya digunakan sekali dan setelah habis maka dibuang. Hal ini akan menimbulkan masalah limbah baterai yang perlu ditangani. Umumnya, baterai yang sudah tidak bisa dipakai lagi perlu didaur ulang dengan melalui suatu proses terstandar. Di Indonesia, penanganan limbah baterai secara umum tertuang dalam suatu Standar Nasional Indonesia (SNI) [Anonim, 2017, Fahad, 2017,Jati, 2019.. Cara lain menangani limbah baterai alkalin adalah dengan cara konservasi yaitu memperpanjang waktu guna baterai melalui pengisian ulang (recharging) (Wijaya, 2015., Roohparvar, 2019)

Kondisi limbah baterai tentu bermacam-macam, karena itu perlu dilakukan pemilahan untuk mengetahui baterai yang masih bisa digunakan kembali. Lebih jauh lagi strategi pengisian ulang juga perlu diteliti sebab mengisi ulang baterai yang tidak didesain untuk diisi ulang, akan beresiko terhadap keamanan atau keselamatan. Resiko keamanan yang dimaksud yaitu kebocoran baterai, panas berlebih atau bahkan meledak. Kemudian mempertimbangkan bahwa baterai jenis apapun mempunyai batas siklus pengisian ulang perlu kiranya diketahui jumlah siklus pengisian ulang efektif baterai alkalin.

Elektroda baterai alkalin terbuat dari metal Zinc (seng) dan Mangan Dioksida. Ukuran baterai standar yang umum di pasaran adalah C, AA, AAA, N, D, dan kotak (9 V). Laju selfdischarge $<0.3 \%$ per bulan. Durabilitas waktu 5-10 tahun tegangan nominal 1.4 V. Lebih tinggi densitas energinya dibandingkan Zinc Carbon atau Zinc Chlorida serta lebih lama shelf-life-nya (wikipedia, 2020). Sedangkan bahan elektrolitnya adalah basa yaitu Potassium Hidroksida $(\mathrm{NaOH})$.

Dilihat dari reaksi kimianya, reaksi kimia dalam baterai dapat dibalik. Sebagian jenis baterai alkaline bisa disi ulang namun sebagian besar tidak bisa sebab akan menyebabkan robekan dan bocor bila diisi ulang. Sumber lain mengatakan bahwa baterai alkalin jenis nonrechargeable bisa diisi ulang namun terbatas hanya kurang dari 10 kali pengisian ulang dan menurun tiap isi ulang. Berbagai cara isi ulang yang sederhana dan cepat meliputi 3 tahap 
daya induksi inteligent daya gerak pengisi pulsa (denyut) tegangan float solar trickle universal USB power bank www candlepower slow charger 15 jam 1/4 kapasitas safety.

Tujuan dari sistem manajemen pengisian baterai adalah untuk memperbaiki pemanfaatan atau penggunaan atau pemaksimalan kapasitas dan lifespan dari baterai Li-ion ukuran besar dan suatu algoritma pengisian baru berbasis pada metode multitahap traditional (Lan et al, 2018)

Beberapa Metode Pengisian Telah diusulkan dntuk mendapatkan kenaikan Life Span Baterai, diantaranya adalah metode tegangan tetap adalah pendekatan yang paling sederhana. Pada metode ini, tegangan dijaga tetap, sementara arus menurun perlahan terhadap waktu. Oleh sebab itu, pengisian melambat ketika baterai mendekati penuh/jenuh. Namun, di lain pihak, menaikkan tegangan untuk mempersingkat waktu pengisian dapat merusak baterai. Pendekatan lain adalah metode arus tetap (constant-current method, CC), yaitu arus dijaga pada suatu nilai tetap dengan cara menaikkan tegangan pengisian. pada cara tersebut, pengisian maksimum dapat dicapai dengan cepat. Namun, tegangan pengisi tanpa batasan tersebut dapat merusak baterai, dan penentuan ketika baterai terisi penuh suatu tantangan tersendiri. Lebih jauh, karena reaksi elektrokimia, tegangan baterai turun secara cepat ketika pengisian dihentikan. Tujuan dari peneltian ini adalah menemukan metoda yang tepat yang dapat dipergunakan untuk mengisi ulang baterai bekas non-rechargeable.

\section{METODE}

Langkah penelitian meliputi tiga tahap yaitu: penentuan cara pemilahan baterai, penentuan strategi pengisian ulang dan prediksi jumlah siklus pengisian ulang. Langkah-langkah penelitian dapat diuraikan sebagai berikut :

\section{Tahap pemilahan baterai}

Langkah pertama penelitian adalah pemilahan baterai bekas type AA. Pemilahan bertujuan untuk memisahkan antara bateri yang masih baik dalam arti masih bisa diisi ulang dan baterai yang telah rusak. Proses pemilahan sebagai berikut: 1) pengamatan fisik secara visual, yaitu melihat apakah ada tanda-tanda kerusakan fisik baterai berupa kecacatan, kebocoran atau keretakan. 2) baterai yang secara fisik terlihat baik kemudian dilakukan pengujian secara listrik, yaitu pengukuran arus hubung singkat dan tegangan hubung buka. Baterai yang memenuhi syarat adalah arus hubung singkat lebih besar dari 0,1 A dan tegangan hubung buka lebih dari $0,7 \mathrm{~V}$. 3) baterai yang memenuhi syarat no 2 diatas kemudian diberikan tegangan pengisi sebesar 1,65 V selama 1 menit, kemudian diukur arus hubung singkat dan tegangan hubung bukanya. Bila terdapat kenaikan arus hubung singkat dan tegangan hubung buka baterai maka baterai tersebut dianggap dapat diisi ulang dan siap untuk tahap percobaan berikutnya

\section{Tahap penentuan strategi pengisian ulang}

Tahap ketiga adalah penentuan strategi pengisian ulang. Berdasarkan jalannya penelitian Percobaan dilakukan pada baterai yang lolos uji deteksi pada tahap sebelumnya. Sumber daya listrik untuk pengisian ulang adalah power supply variabel dengan tegangan dan arus yang bervarisi. Dari power supply akan terhubung ke baterai yang akan diuji. Selanjutnya baterai tersebut akan dengan proses mengisi ulang baterai menggunakan 3 metode yaitu metode tegangan konstan, metode arus konstan dan metode tegangan tetap -arus tetap. Selama baterai mengisi akan dihubungkan amperemeter untuk pengukuran arus, voltmeter untuk tegangan, serta timer untuk mengukur waktu. Rangkaian pengujian terlihat pada Gambar 1. 


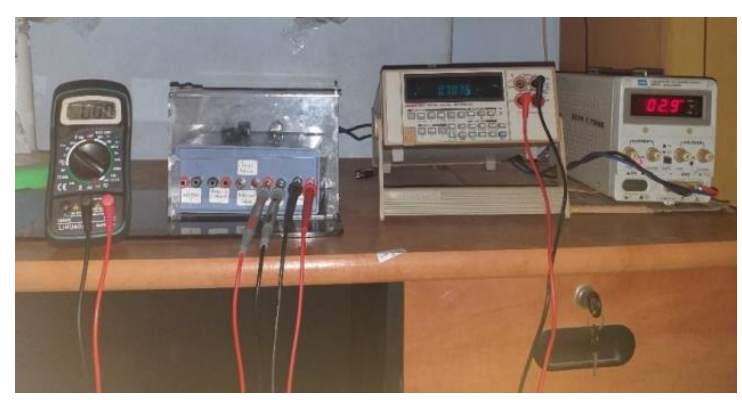

Gambar 1. Rig Experimen penelitian pengisian ulang baterai alkalin yang terdiri dari pembangkit tegtangan (voltage generator), Ampere meter, Volt meter dan timer

Untuk memastikan kondisi baterai dalam kondisi baik dan tidak mengalami kebocoran, baterai bekas yang sudah tak terpakai di ukur dan selanjutnya baterai dikosongkan kembali sampai baterai mencapai tegangan dan arus yang sama dengan meletakan baterai pada tempat pengosongan atau discharge. Didapatkan kondisi baterai memiliki tegangan yaitu 1.11 Volt dan arus pada baterai atau $I_{s c}$ memiliki 1 A. Setelah baterai dalam kondisi yang sama, selanjutnya di lakukan pengisian dengan meletakkan baterai pada tempat uji yang telah di lapisi dinding akrilik tembus pandang agar dapat mengetahui kondisi baterai. Terdapat power supplay dan 2 multimeter. Salah satu multimeter mengukur Tegangan dan multimeter lainnya mengukur arus. Selama pengujian, baterai alkaline non-rechargeable dengan ukuran AA diperlakukan 3 metode pengisian yaitu metode pengisian dengan tegangan konstan, metode pengisian arus konstan dan terakhir dengan metode kombinasi tegangan dan arus konstan dengan rentang waktu pengukuran adalah 15 menit dan 10 menit.

\section{Tahap Perkiraan Jumlah Siklus Pengisian Efektif}

Tahap selanjutnya adalah perkiraan junlah siklus pengisisan efektif. Bahan yang digunakan pada tahap ini adalah baterai alkalin bekas yang sudah melalui tahap pemilihan dengan proses pemilahan dan menggunakan detektor kerusakan baterai yang sudah dibuat sebelumnya yang merupakan hasil dari tahap pertama. Kemudian baterai tersebut akan dikosongkan hingga arus hubung singkat tertentu, dalam hal ini ditetapkan 0,1 A. Pengosongan atau discharge dilakukan dengan menghubungkan beterai ke baban resistor 1 Ohm. Selanjutnya dilakukan pengisian dengan alat pengisi yang sesuai dengan hasil pada tahap kedua. Proses pengosongan dan pengisian tersebut dilakukan berulang, hingga baterai tidak dapat diisi kembali atau mengalami kerusakan. Jumlah siklus pengosongan-pengisian kemudian dihitung.

Pada penelitian ini variabel yang akan di cari dalam pengolahan data adalah:

a. Arus, Baterai akan dilihat grafik arus, dimana akan menunjukan kondisi arus pada baterai dan kemampuan baterai dalam menyimpan arus setelah dilakukan pengujian pengisian dengan metode yang ada.

b. Tegangan, Baterai akan dilihat grafik tegang, dimana akan dilihat kondisis tegangan listrik pada baterai dan kemampuan baterai dalam menyimpan tegangan setelah dilakukan pengujian pengisian dengan metode yang ada

Proses pengisian dilakukan dalam batas waktu 10 menit, dalam batas waktu 10 menit multimeter juga dihubungkan kebaterai. Pada penelitian ini data berjumlah 9 buah baterai dengan kondisi bekas 


\section{HASIL DAN PEMBAHASAN}

\section{Hasil penentuan strategi pengisian ulang}

Hasil pengukuran pengisian baterai dengan tegangan konstan dan arus variable dimana diberikan arus sebesar $500 \mathrm{~mA}$ dan tegangan $3 \mathrm{~V}$ diperlihatkan pada Gambar 2. Pengisian dilakukan dalam kurun waktu 15 menit dan waktu jeda tertentu dan mengukur kembali tegangan dan arus hubung singkat baterai.

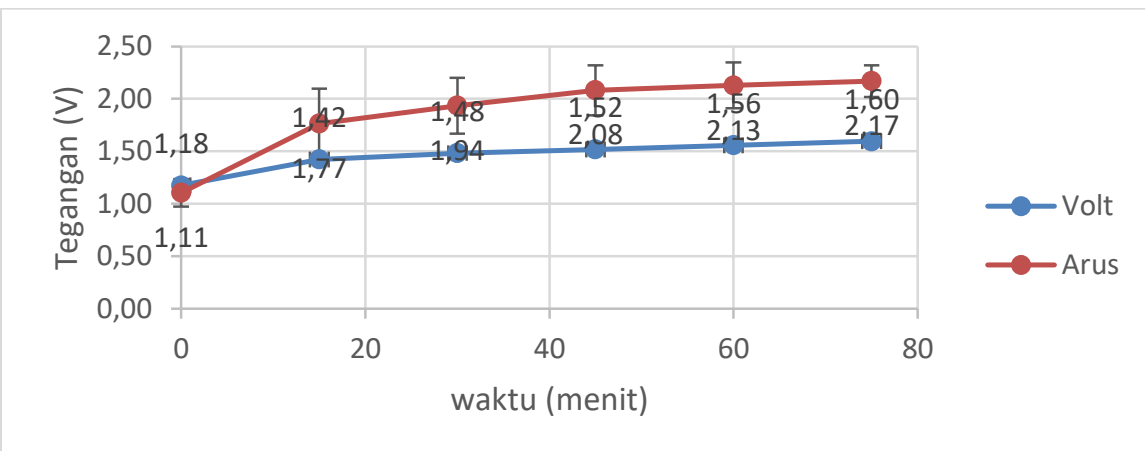

Gambar 2. Kurva tegangan dan arus hubung singkat baterai terhadap waktu pengisian baterai metode tegangan konstan

Pada kurva nilai rata-rata dari pengujian Gambar 2 terlihat tegangan hubung terbuka baterai (garis berwarna biru) degan kondisi awal $1.175 \mathrm{~V}$ mengalami kenaikan dengan nilai yang variatif. Pada 15 menit pertama mengalami kenaikan sebesar 1.422 dengan selisih $0.25 \mathrm{~V}$. Untuk 15 menit selanjutnya tidak mengalami kenaikan tetap berada pada sekitar $1.4 \mathrm{~V}$, dan kembali meningkat naik pada menit ke 45 dengan selisi kenaikan $0.03 \mathrm{~V}$. Pada menit ke 45 hingga menit 75 tegangan mengalami kenaikan yang lambat namun tetap berada di sekitaran tegangan $1.5 \mathrm{~V}$. Proses pengisian terhenti pada menit ke 75 dengan tegangan baterai rata-rata terukur sebesar 1.59. Sedangkan untuk arus pada baterai yang garis berwarna kuning dengan arus awal sebesar 1.1A, selama proses pengisian berlangsung pada 15 menit pertama arus pada baterai mengalami kenaikan yang begitu tinggi hingga $1.76 \mathrm{~A}$ dengan selisi $0.6 \mathrm{~A}$. Selanjutnya untuk 15 menit berikutnya arus mengalami kenaikan namun tidak terlalu tinggi dengan selisih rata-rata $0.1 \mathrm{~A}$. Hingga pada menit ke 60 dan menit ke 75 baterai tidak mengalami kenaikan dengan nilai 2.1A. Proses charger berhenti pada menit 75 dengan nilai arus terukur hubung singkat atau $\mathrm{I}_{\mathrm{sc}}$ sebesar 2.17A.

Pengujian selanjutnya dengan metode pengisian arus konstan dan arus varibel, sama halnya dengan metode pengisian dengan tegangan pengisian $3 \mathrm{~V}$ dan untuk arus range adalah $550 \mathrm{~mA}$ diperlihatkan pada Gambar 3. 


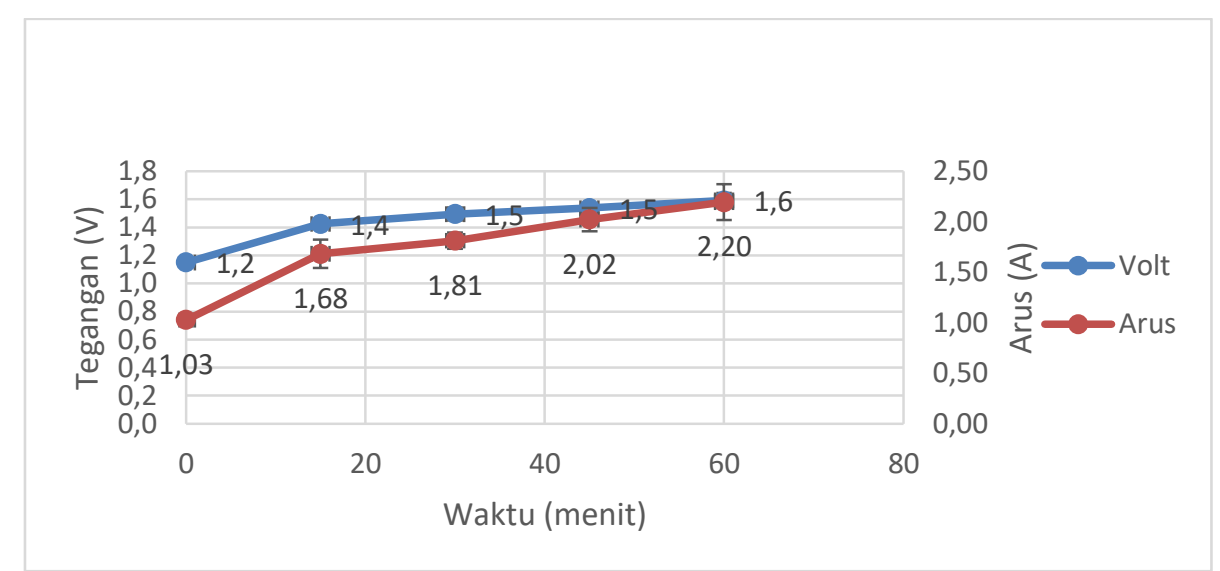

Gambar 3. Kurva tegangan dan arus hubung singkat baterai terhadap waktu pengisian baterai metode arus konstan

Pada Gambar 3 yang memperlihatkan kurva nilai rata-rata pengujian terlihat bahwa tegangan (garis berwarna biru) dengan kondisi awal $1.15 \mathrm{~V}$ terus mengalami kenaikan. Pada 15 menit pertama mengalami kenaikan sebesar $1.42 \mathrm{~V}$ dengan selisih $0.27 \mathrm{~V}$. Untuk 15 menit selanjutnya tidak mengalami kenaikan tetap pada rentang di tegangan $1.4 \mathrm{~V}$, namun kembali naik pada menit ke 45 dengan tegangan sebesar $1.53 \mathrm{~V}$. Hingga menit ke 60 tegangan berada di sekitaran tegangan $1.5 \mathrm{~V}$. Proses pengisian terhenti pada menit ke 60 dengan tegangan baterai rata-rata terukur sebesar 1.59 .

Sedangkan untuk arus pada baterai yang garis berwarna kuning dengan arus awal sebesar 1.02. Selama proses pengisian berlangsung, pada 15 menit pertama arus pada baterai mengalami kenaikan yang begitu tinggi hingga 1.68 A. Selanjutnya untuk 15 menit berikutnya arus terus mengalami kenaikan namun tidak terlalu tinggi dengan selisih rata-rata $0.2 \mathrm{~A}$. proses charger lebih cepat berhenti yaitu pada menit 60 dengan nilai arus terukur hubung singkat atau Isc sebesar 2.19A.

\section{Metode Pengisian Tegangan Dan Arus Konstan}

Pada proses dengan metode kombinasi metode tegangan konstan dan arus konstan pengisian baterai dilakukan dengan dua metode sekaligus secara bergantian dengan selang waktu 10menit. Sama halnya dengan metode-metode sebelumnya, baterai akan di berikan tegangan dan arus sebesar $3 \mathrm{~V}$ dan $550 \mathrm{~mA}$. Selama selang 10 menit, demikian juga baterai akan di ukur untuk melihat tegangan dan arus pada baterai, sebelum metode berganti. Data hasil pengujian diperlihatkan pada kurva Gambar 4

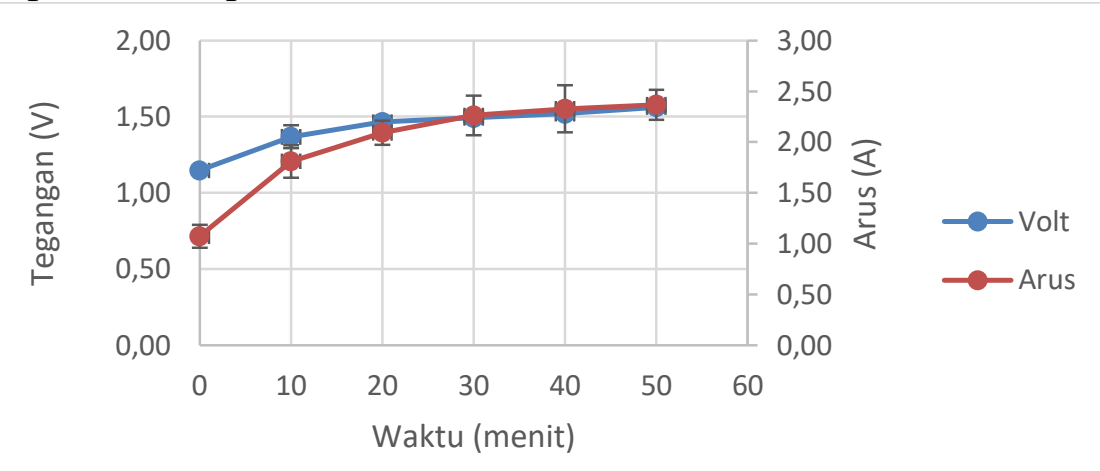

Gambar 4. Kurva tegangan dan arus hubung singkat baterai terhadap waktu pengisian baterai metode tegangan konstan-arus konstan 
Pada Gambar 4 dapat dilihat tegangan hubung terbuka baterai ( garis berwarna biru) degan kondisi awal $1.14 \mathrm{~V}$ terus mengalami kenaikan. Pada 10 menit pertama mengalami kenaikan sebesar $1.368 \mathrm{~V}$ selisi $0.3 \mathrm{~V}$, untuk 10 menit selanjutnya mengalami kenaikan tetapi tidak terlalu tinggi dengan selisih naiknya sebesar $0.1 \mathrm{~V}$. Pada 10 menit berikutnya yaitu pada menit ke 20 dan menit ke 30 tidak mengalami kenaikan yaitu pada rentang di tegangan 1.4 V. Namun kembali naik pada menit ke 40 dengan tegangan sebesar $1.52 \mathrm{~V}$. Hingga menit ke 50 tegangan tetap berada di sekitaran tegangan $1.5 \mathrm{~V}$. Proses pengisian terhenti pada menit ke 50 dengan tegangan baterai terukur sebesar 1.56.

Sedangkan untuk arus pada baterai yang garis berwarna kuning denga arus awal sebesar 1.07A. Selama proses pengisian berlangsung pada 10 menit pertama arus pada baterai mengalami kenaikan yang begitu tinggi hingga $1.81 \mathrm{~A}$ selisih naiknya sebesar $0.8 \mathrm{~A}$. Selanjutnya untuk 10 menit berikutnya arus terus mengalami kenaikan tinggi dengan selisih rata-rata 0.2 A Hingga pada menit ke 40 dan menit ke 50 arus tidak mengalam kenaikan, berada tetap di sekitaran 2.3A. Proses charger berhenti pada menit 50 dengan nilai arus terukur hubung singkat atau $\mathrm{I}_{\mathrm{sc}}$ sebesar 2.39A.

\section{Perbandingan hasil metode pengisian}

Dari ke 3 metode pengisian yang telah diterapkan, terdapat perbedaan untuk kurva arus pada tiap metode selama proses mengisian berlangsung. Dari Gambar 2, 3 dan 4 terilihat bentuk kurva yang dihasilkan untuk semua metode mengalami kenaikan selama proses pengisian berlangsung, namun saja terdapat perbedaan nilai arus yang terukur serta waktu dalam mencapai titik puncak nilai arus. Dari 3 metode tersebut pengisian lebih tinggi dan cepat mencapai titik puncak adalah dengan metode kombinasi tegangan dan arus konstan, yakni mencapai puncak pada waktu 50 menit. Untuk metode pengisian arus konstan pencapaian titik puncak di menit 60 dengan selisih jauh dengan metode kombinasi tegangan dan arus konstan, dapat dilihat pula pada waktu 15 menit berikutnya mengalami peningkatan yang melambat. Dan terakhir yaitu metode tegangan konstan, kurva yang di bentuk juga menampilkan kenaikan, namun pada waktu 45 menit nilai arus yang dihasikan mulai tetap dan titik puncanya berada pada waktu 75 menit selisi dibawah dari 2 metode sebelumnya.

Berdasarkan kurva nilai arus hubung singkat dapat diperoleh bahwa metode dengan nilai arus yang tinggi dan cepat mencapai titik puncak tegangan pada baterai dari 3 metode pengisian yang diuji adalah pengisian dengan metode kombinasi tegangan dan arus konstan yang hanya membutuhkan waktu 50 menit dan nilai tegangan pun memiliki nilai cukup tinggi. Terakhir diperoleh dari 27 baterai yang diuji didapat bahwa dengan menerapkan metode pengisian tegangan konstan - arus konstan didapat rata-rata 8 kali pengisian ulang sebalum baterai menjadi rusak atau tidak bisa diisi lagi.

Hasil penelitian membuktikan bahwa baterai bekas non-rechargeable ternyata masih dapat diisi ulang / dicharge dengan menerapkan procedure dan metoda pengisian tertentu. Hasil ini merupakan pembuktian awal yang masih perlu ditindaklanjuti dengan penelitain lanjutan untuk memastikan keamanan sistem pengisiannya. Hasil ini berbeda dengan pendapat para ahli yang menyakatan baterai non-rechargeable tidak dapat diisi ulang. (Niel, 2021 )

\section{KESIMPULAN}

Baterai alkaline non rechargeable yang masih dapat disi ulang adalah bila tegangan tersisa lebih dari 0.9 volt dan tidak terdapat kebocoran. Adapun metode terbaik yang digunakan mengisi baterai alkalin non-rechargeable adalah dengan metode kombinasi tegangan konstan dan arus konstan. Dalam pengisian nilai tegangan dan arus untuk satu baterai alkalin dengan 
ukuran AA adalah sebesar $3 \mathrm{~V}$ dengan arus sebsesar $550 \mathrm{~mA}$. Baterai alkaline non rechargeable dapat diisi ulang rata-rata hingga 8 kali.

\section{Ucapan Terima Kasih}

Terima kasih ditujukkan kepada LPPM Universitas Mataram atas kerjasama dan dukungan pendanaan serta bantuan lainnya. Terima kasih juga ditujukan untuk teman-teman yang tergabung di Kelompok Riset Power Electronics and Drives, Universitas Mataram dan juga untuk I Komang Yudhi Satya Nugraha, mahasiswa Teknik Elektro Universitas Mataram atas kontribusinya dalam melaksanakan eskperimen yang cukup menyita waktu.

\section{DAFTAR PUSTAKA}

Fast M.R., 2020., Alkaline Battery Market Insights, Trends, Opportunity \& Forecast https://www.fastmr.com/report/28/alkaline-battery-market.

Kemenperin, 2014. Perkembangan Jumlah Unit Usaha Industri Besar dan Sedang di Indonesia, dapat diakses pada https://kemenperin.go.id/statistik/ibs_indikator.php?indikator $=1$, tanggal akses 19-01-2020

Anonim, 2017. All About Batteries: Environmental Fact Sheet, New Hampshire Departement of Enviromental Services

Fahad, H., 2017. Cara memproses daur ulang baterai bekas. https://www.jk2lhpurwakarta.org/2017/12/Daur-ulang-baterai-bekas.html diakses 27 Des 2019

Jati, Y. W., 2009. Baterai dikenai SNI wajib. https://bsn.go.id/main/berita/berita_det/935/Bateraidikenai-SNI-wajib diakses 27 Des 2019.

Wijaya, C. D., 2015. Mau perpanjang usia baterai alkaline? pakai alat ini aja! https://jalantikus.com/news/6376 diakses 2 Januari 2020

Roohparvar, B., 2019. Batteroo: Extend battery life significantly. https://www.indiegogo.com/projects/batteroo-extend-battery-life-significantly\#/ diakses 27 Des 2019.

Lan, C. W., Lin, S. S., Liu, H. Y., Chen, L. H., and Huang, T. C., 2018. The development of portable intelligent battery management system with adequate charging method, Journal of the Chinese Institute of Engineers, vol. 41, no. 8, pp. 678-686.

Niel, M. 2021. How to recharge a non-rechargeable battery. ttps://batterymanguide.com/howto-recharge-a-non-rechargeable-battery/, diakses 28-10-2021. 